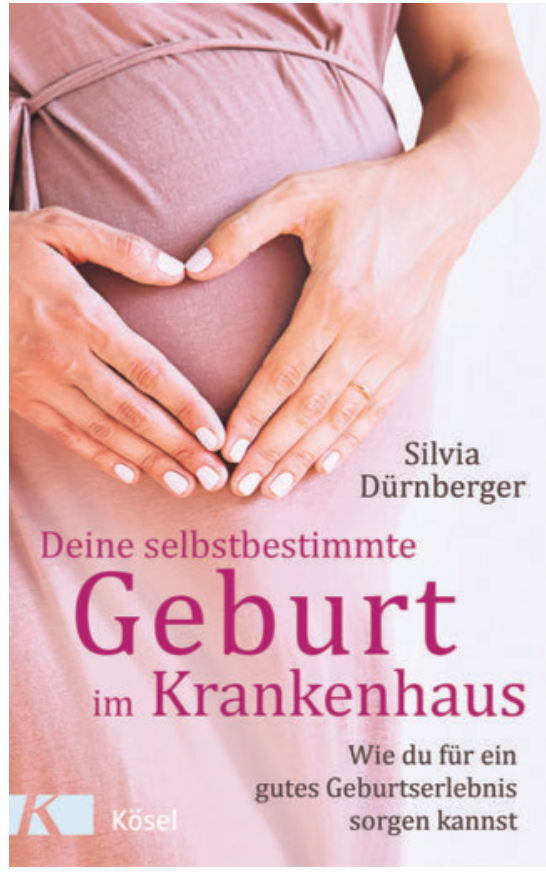

Neuerscheinung

\section{Deine selbstbestimmte Geburt im Krankenhaus}

Die Mehrheit der werdenden Eltern in Deutschland entscheidet sich für eine Geburt im Krankenhaus, wünscht sich jedoch, dort möglichst individuell betreut zu werden. Der vorliegende Ratgeber kann Paaren helfen, sich konkret auf die Geburtssituation in einer Klinik vorzubereiten. Die Autorin ist Familien- und Paarberaterin und vierfache Mutter. Mit ihrem Buch will sie viel erreichen: „Ich habe es geschrieben, weil ich davon träume, dass du - ebenso wie jede andere Frau - an der Klinik deiner Wahl die achtsamste und persönlichste Begleitung zur Verwirklichung deiner Wünsche während der Geburt deines Kindes erhältst.“

Damit dieser Traum in Erfüllung gehen kann, schildert Silvia Dürnberger im ersten Teil, welche medizinischen Angebote es in Geburtskliniken gibt und welche Fachleute dort arbeiten. Fragebögen sollen der Leserin helfen, die für sie richtige Geburtsklinik auszuwählen. Der zweite Teil widmet sich der persönlichen Geburtsvorbereitung, schildert die Geburtsphasen und formuliert die Aufgaben des Partners während der Geburt.
Geburtsberichte und ein Ausblick auf die erste Zeit nach der Geburt runden das Buch ab.

Ich halte dieses Buch für den idealen Einstieg für alle Schwangeren, die ihr erstes Kind erwarten und eine Klinikgeburt planen. Wenn sich in der Geburtshilfe etwas ändern soll, werden selbstbewusste und aktive Gebärende gebraucht oder wie Dr. Sven Hildebrandt in seinem Vorwort schreibt: „Wir brauchen dieses Buch dringend, wir brauchen ein Wachrütteln der Frauen in der Beziehung zu ihrem Körper und zu ihrer Geburt-und wir brauchen die selbstbestimmte Gebärende, die ihre Geburt zu gestalten vermag.“

Katharina Kerlen-Petri

Titel: Deine selbstbestimmte Geburt im Krankenhaus

Autor: Silvia Dürnberger

Kategorie: Ratgeber

Verlag: Kösel

Jahr: 2019

Preis: 20 Euro

\section{Neuerscheinung}

\section{Papipedia. Alles, was Väter und ihre Kinder brauchen}

Der amüsante Buchtitel macht neugierig! Werden in diesem Buch mit der humorvollen Parallele zu Wikipedia alle Fragen zur Vaterschaft umfänglich beantwortet? Die Antwort ist eindeutig: Ja. Autor Christian Gaca ist Vater von vier Kindern, verheiratet mit einer Hebamme und blickt auf 14 Jahre gelebte Familienerfahrung zurück. Erfahrungen, die Väter künftig im Alltag machen - denn seiner Ansicht nach haben viele Männer einfach falsche Vorstellungen davon, welche Veränderungen durch den Familienzuwachs auf sie zukommen.

Das Buch greift die wichtigsten Aspekte rund um Schwangerschaft, Geburt und das Leben mit Kindern auf-gepaart mit amüsanten Geschichten aus dem Familienleben des Autors und ernsthaften Überlegungen zum Vaterwerden und -sein. Die Themen sind übersichtlich in Zeitabschnitte wie Trimester, Geburt und die

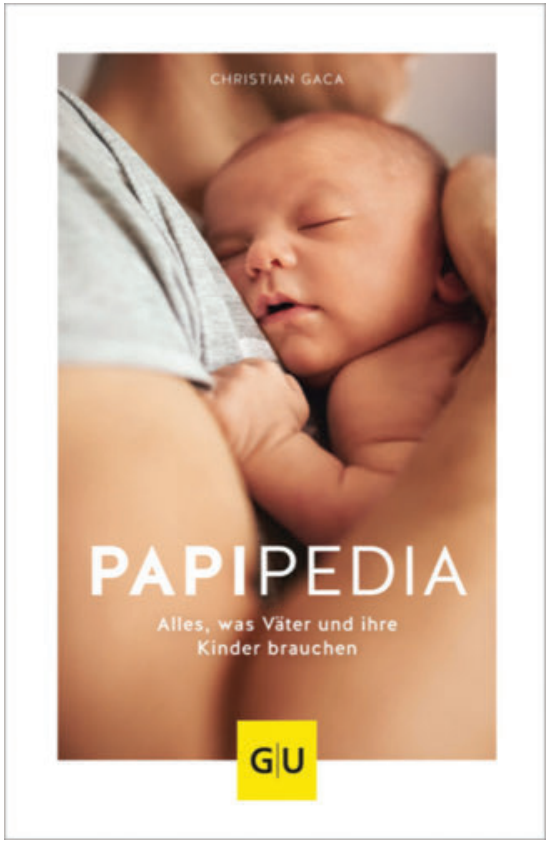

Zeit danach untergegliedert. Zu jeder Phase werden Fragen beantwortet, die sich Väter stellen können. Dabei geht es u. a. um Pränataldiagnostik, Ultraschalluntersuchungen, Geburtsort, Babyausstattung und Tragen.

Der Autor legt Wert darauf, dass Männer nach der Lektüre in der Lage sind, individuelle Entscheidungen zu treffen. Neben hoher Fach- und Sachkompetenz ist die emotionale Wertschätzung gegenüber Frau und Mann in jedem Kapitel spürbar. Es macht Freude, zu lesen wie Mann „tickt“ und wie Gaca die Stimmungsschwankungen, Gefühle bei der Geburt und Krisen im Wochenbett beschreibt. Er lässt Väter zu Wort kommen und berichtet mit viel Detailwissen.

Mir haben die angenehme Bescheidenheit des Autors, die ehrlichen Worte und die ausbleibenden Beschönigungen gefallen. Es ist für mich das erste Buch für Väter, das ausnahmslos das Prädikat „besonders wertvoll“ verdient hat!

Petra Wittig

Titel: Papipedia. Alles was Väter und ihre Kinder brauchen

Autor: Christian Gaca

Kategorie: Ratgeber

Verlag: Gräfe und Unzer

Jahr: 2019

Preis: 16,99 Euro 